\title{
An Illustration of a Deductive Pattern Matching Procedure in Qualitative Leadership Research
}

\author{
Noel Pearse \\ Rhodes University, Grahamstown, South Africa \\ N.Pearse@ru.ac.za \\ DOI: $10.34190 / J B R M .17 .3 .004$
}

\begin{abstract}
Most qualitative studies in business-related research have adopted an inductive approach, in that they explore specific cases and then extract themes, or statements that are more general, from this data. This approach has its shortcomings, including not developing a more systematic body of knowledge of behavioural and social processes that take place in organisations. In contrast, in deductive qualitative research, the theoretical propositions derived from a review of the literature serve as its departure point, informing how the data is collected. Later on in the analysis of data, the researcher uses the propositions to determine if the literature explains the case that was being investigated. Unfortunately, given the relative neglect of deductive qualitative research approaches, there is little guidance and few examples offered that illustrate the application of these techniques. This poses a challenge for researchers, who often need a greater level of structure when it comes to designing and conducting their research. Therefore, the aim of this paper is to illustrate the design of a research protocol that integrates two deductive approaches that are suitable for explanatory case study research, namely deductive thematic analysis and pattern matching. This paper develops a sevenstep process that researchers can follow, for carrying out this type of deductive qualitative research. Using extracts from a research study investigating the leading of organisational change, the steps in this process are illustrated.
\end{abstract}

Keywords: thematic analysis, pattern matching, case study research, deductive qualitative analysis, leading organisational change

\section{Introduction}

There is proportionately less qualitative research published in business research when compared to studies of a quantitative nature (Bryman 2004; Fischer, Dietz, \& Antonakis 2017). The consequence of this relative neglect of qualitative research is that there is a superficial understanding of, and little theory development related to the behavioural and social processes that take place in organisations and business (see for example, Brown 2018; DeRue \& Ashford 2010; Fischer et al. 2017). In addition, research results have become removed from real experiences and behaviours (Higgs \& Rowland 2011).

On the other hand, referring to leadership research in particular, Bryman (2004) bemoans the tendency of qualitative researchers, who - in adopting an ideographic and inductive approach - do not engage in prior theoretical conjecture. As a result, by exploring particularly unique cases and then inductively extracting themes or general statements, on they do not build upon the work of other researchers, thereby undermining attempts to develop a body of knowledge that is distinctive to qualitative leadership research.

Deductive qualitative research can be differentiated from other qualitative approaches in that it takes as its departure point, the theoretical propositions that are derived from a review of the literature and applies these to the collection and analysis of data (Boyatzis 1998; Fereday \& Muir-Cochrane 2006; Hyde 2000). The appeal of deductive qualitative analysis is evident in its recommended use in case studies, with Robert Yin (Yin 2014) widely regarded as a major proponent of the case study method - having adopted a deductive approach (Riege 2003) in the development of his version of the case study method. Deductive analysis is particularly relevant for explanatory case studies (Fisher \& Ziviani 2004).

However, only a small portion of qualitative studies has adopted a deductive approach (e.g. Denis, Langley, \& Pineault 2000). Since deductive qualitative analysis has been neglected, there is little guidance and few examples offered that illustrate the application of these techniques. This poses a challenge for students and novice researchers in particular, who need a greater level of structure when it comes to designing and conducting their research. Therefore, the aim of this paper is to illustrate the combined application of two deductive analytical approaches that are suitable for case study research design, namely deductive thematic analysis and pattern matching. It does so by using extracts from a research study investigating the leading of organisational change to illustrate the steps in this process. This larger study was conducted amongst a 
number of organisations that had experienced internal resistance to the changes that they had introduced to adapt to their changing environment, and investigated how the leaders had dealt with this resistance and what the reaction and outcomes were to the leader's response.

The remainder of the paper is structured as follows. Firstly, the data analysis techniques of deductive thematic analysis and pattern matching are introduced and briefly discussed. Thereafter a seven-step process for deductive qualitative research with pattern matching is described. Each step is illustrated with extracts from a larger study investigating the leading of organisational change, before concluding the paper.

\section{Deductive Thematic Analysis}

"Thematic analysis is a method for identifying, analysing and reporting patterns (themes) within data" (Braun \& Clarke 2006, p. 79). Thematic analysis is used regularly and flexibly in qualitative data analysis, and there have been several attempts to provide a more systematic approach to its use. However, most authors have combined deductive and inductive versions to create a hybrid approach (Braun \& Clarke 2006; Fereday \& MuirCochrane 2006; Rishi, Jauhari, \& Joshi 2015), and only a few authors have set out differentiated processes for these alternatives (see for example, Boyatzis 1998).

The deductive version of thematic analysis, or theoretically-driven coding, uses theory as its point of departure (Boyatzis 1998). Jones et al. (2018) illustrate how theory informed their analysis, with their coding frame based on the conceptualization of community capacity that was developed by Edwards (2015). Boyatzis (1998) and Fereday and Muir-Cochrane (2006) describe and illustrate the steps of deductive thematic analysis, which include: (1) Considering sampling and design issues; (2) Developing the code manual (This entails labelling, defining and describing when the theme occurs); (3) Validating or testing the reliability of the code; (4) Summarizing data and identifying initial themes; (5) Applying the template of codes and additional coding; (6) Connecting the codes and identifying themes; and (7) Corroborating and legitimating coded themes.

\section{Pattern matching}

Pattern matching was originally described by Campbell (1975) and is one of the forms of analysis that is recommended for case study research (Hyde 2000; Yin 2014), particularly to enhance the internal validity (Gibbert, Ruigrok, \& Wicki 2008), or rather, the credibility of the study (Riege 2003). Pattern matching has its origins in quantitative studies using small samples (Campbell 1975). Its usefulness and appeal was in identifying patterns in small data sets and in testing hypotheses. However, it can also be used qualitatively, and in this qualitative form, complements deductive thematic analysis techniques (Hyde 2000).

Pattern matching involves identifying the patterns in data, and then comparing this against one or more patterns that are proposed in the literature (Almutairi, Gardner, \& McCarthy 2014; Gibbert et al. 2008). Before starting with data-gathering, the theory to be tested is stated (Hyde 2000). Two alternate theories (or more) are put forward for testing, which typically set out competing patterns of outcomes that are then tested empirically (Almutairi et al. 2014). These patterns may contain one or more dependent variables that are related to one or more independent variables (Almutairi et al. 2014). Examples of leadership studies that have used pattern matching include Denis et al. (2000), who have combined managerial control and socialisation perspectives to explore the integration of a new leader into an organisation, while Murphy and Ensher (2008) applied pattern matching to investigate if the leadership behaviour of television directors matches the theory of charismatic leadership.

Pattern matching typically requires analysing several cases or incidents. See Hyde's (2000) application in testing the models "independent travel as evolving itinerary" versus "independent travel as planned itinerary" as an example. However, pattern matching can be used when conducting research on a single case, and by using at least two differentiated theories in the process of data collection and analysis (Yin 1981). In the selection of a single case, Yin (1981) notes that this is based on the occurrence of a phenomenon in its real life context, since case study research is concerned with the occurrence of a phenomenon in, and is not divorced from its dynamic context, but rather inseparable from it. He further notes that because it seems to disconfirm the conventional explanation or theory, a researcher may intentionally select a non-exemplary case. In this way, he argues, single cases provide valid tests of a theory; but also do so by following an ideographic approach rather than a nomothetic one. While there may be some scepticism in using a single case, the depth 
and contextual insights from single case studies have proven to be useful in the past for building theory (Dyer \& Wilkins 1991).

Furthermore, according to Yin (1981, p. 108) "data from a single case can be used to test a theory (i.e., a pattern), as long as contrary theories are also compared". Later, Yin (2003, p. 118) argues that each of these alternate explanations or "rival theoretical propositions ... involves a pattern of independent variables that is mutually exclusive. If one explanation is to be valid the others cannot be". However, this is not necessarily the case, as advocates of theory triangulation (Hopper \& Hoque 2006) would argue, it is possible for different theories - even those with fundamentally different assumptions and traditions - to complement one another and provide a fuller explanation of a phenomenon, or research problem.

According to Hyde (2000, p. 86) pattern matching involves the following steps: “(1) theoretical propositions are stated before data-gathering commences; (2) a counter-theory is also stated; (3) a case-by-case comparison of the deductive dataset with the theory and the counter-theory is undertaken by independent judges; (4) a record of hits and misses is recorded".

\section{A Research Procedure for Deductive Qualitative Research with Pattern Matching}

As indicated earlier, the aim of this paper is to illustrate the combined application of deductive thematic analysis and pattern matching. In fulfilling this aim, the first objective is to set out a clear procedure for researchers to follow who are interested in conducting deductive qualitative research. In support of this objective, additional sources are identified that illustrate many of these steps, and to which researchers can refer. The second objective is to illustrate the application of this process using an example of leading organisational change. In order to combine deductive thematic analysis and pattern matching in a coherent manner, the following seven steps are suggested:

\subsection{Step 1: Conceptual Framework}

Conducting a literature review should culminate in a conceptual framework for the study. "A conceptual framework explains, either graphically or in narrative form, the main things to be studied-the key factors, variables, or constructs-and the presumed interrelationships among them. Frameworks can be simple or elaborate, commonsensical or theory driven, descriptive or causal. ... A conceptual framework forces you to be selective-to decide which variables are most important, which relationships are likely to be most meaningful, and, as a consequence, what information should be collected and analyzed-at least at the outset" (Miles, Huberman, \& Saldaña 2014, p. 37). Examples of such frameworks are Uysal \& Tsetsura (2015) who explore stakeholder activism and the process and outcomes related to shareholder resolutions. When pattern matching is being applied, there will be at least two frameworks, one for each of the competing theories, but these can be integrated into a single figure or framework. See the initial conceptual model of Denis, Langley, and Pineault (2000) as an example of this.

The research problem that is to be illustrated in this paper is "How do leaders as agents of change go about designing and redesigning an organisational change intervention in response to various stakeholders, and with what effect?" This statement is developed further into the conceptual framework presented in Figure 1, through several considerations that emerged from a review of the literature.

Firstly, a stakeholder perspective of strategy and change (Freeman 1984; 2004) recognises that organisations interact in different ways with a diversity of internal and external stakeholders, and that therefore a stakeholder analysis should be incorporated into the formulation and implementation of strategy, or the design of organisational change initiatives. Stakeholders have a range of expectations of organisations, some of which can be accommodated and others not. This requires organisations to identify the stakeholders and their expectations and to consider the implications of either responding or not responding to these expectations as part of formulating and implementing organisation strategy. The strategic leadership of the organisation (1) identifies various primary and secondary stakeholder groups and key stakeholders within those groups (Freeman, Harrison \& Wicks 2007); (2) identifies their needs and expectations of the organisation; (3) assesses their importance by rating or mapping them on dimensions such as power, interest, legitimacy, and urgency (Mitchell, Agle, \& Wood 1997; Newcombe 2003); (4) considers the implications of this analysis for the organisation's strategy; and (5) then decides if and how to engage with the various stakeholder, and on what issues (Arnstein 1969; Krick, Forstater, Monaghan \& Sillanpää 2005). Consequently, planned change in organisations typically occurs through top-down initiatives by leadership in response to 
external stakeholders, and/or through inside out change processes in response to internal stakeholders (Lozano, Nummert, \& Ceulemans 2016).

Secondly, it is widely recognised that organisational inertia and/or resistance to change is likely to occur in response to change initiatives, and is often the cause of the failure of planned change (Kotter 2007; Pearse, 2010). In response, organisational change agents often redesign the change programme, either proactively in anticipation of resistance, or reactively when resistance is observed so as to effectively manage resistance to change (Kotter \& Schlesinger 2008).

Thirdly, management practitioners often refer to "hard" and "soft" issues that they need to deal with when managing change. There is some support for this distinction in the scholarly literature (Mathews 2009; Smulders, Caluwe, \& Nieuwenhuizen 2003; Truss 1999), and it is also referred to elsewhere as the people versus techno centric elements (Lozano et al. 2016), behavioural versus non-behavioural components (Mathews 2009), Theory E and Theory O (Beer \& Nohria 2000) or the intangible versus tangible dimensions of change (Huy 2001). The "hard" elements include raw materials, products, organisation structure, systems and processes; while examples of the "soft" elements include organisational vision, values and culture, policies and practices, education and training and socialisation (Huy 2001; Lozano, Ceulemans, \& Scarff Seatter 2015; Lozano et al. 2016; Mathews 2009). Furthermore, in response to external stakeholders, leaders often design change initiatives that consist of "hard" elements, while in response to internal stakeholders (e.g. employees) change initiatives tend to focus more on "soft" elements (Lozano et al. 2016).

Finally, it has been suggested that leaders' responses to change emphasise control and/or trust (Neves \& Caetano 2006). Change can create feelings of insecurity, fear and anxiety in employees, particularly when they experience a sense of loss during a change process, or believe that the change threatens their job security (Caruth, Middlebrook, \& Rachel 1985; Hui \& Lee 2000). Therefore the response of leaders is critical in allaying employee concerns and anxieties, and creating a sense of personal safety and control for them. Judge and Elenkov (2005) highlight the importance of trustworthy leadership during a change initiative. This trust can develop when leaders act decisively and capably, and successfully lead the organisation through change to meet organisational goals, and thereby demonstrate that they are in control (Judge \& Elenkov 2005; Neves \& Caetano 2006). Alternatively, leaders may engage in trust building initiatives with employees to give them assurance (Neves \& Caetano 2006).

In summary, the conceptual framework is illustrated in figure 1. What is more, the framework has integrated two competing explanations of the design of change interventions, namely one that emphasises "hard" interventions and leader control, while the other emphasises "soft" interventions and trust building.

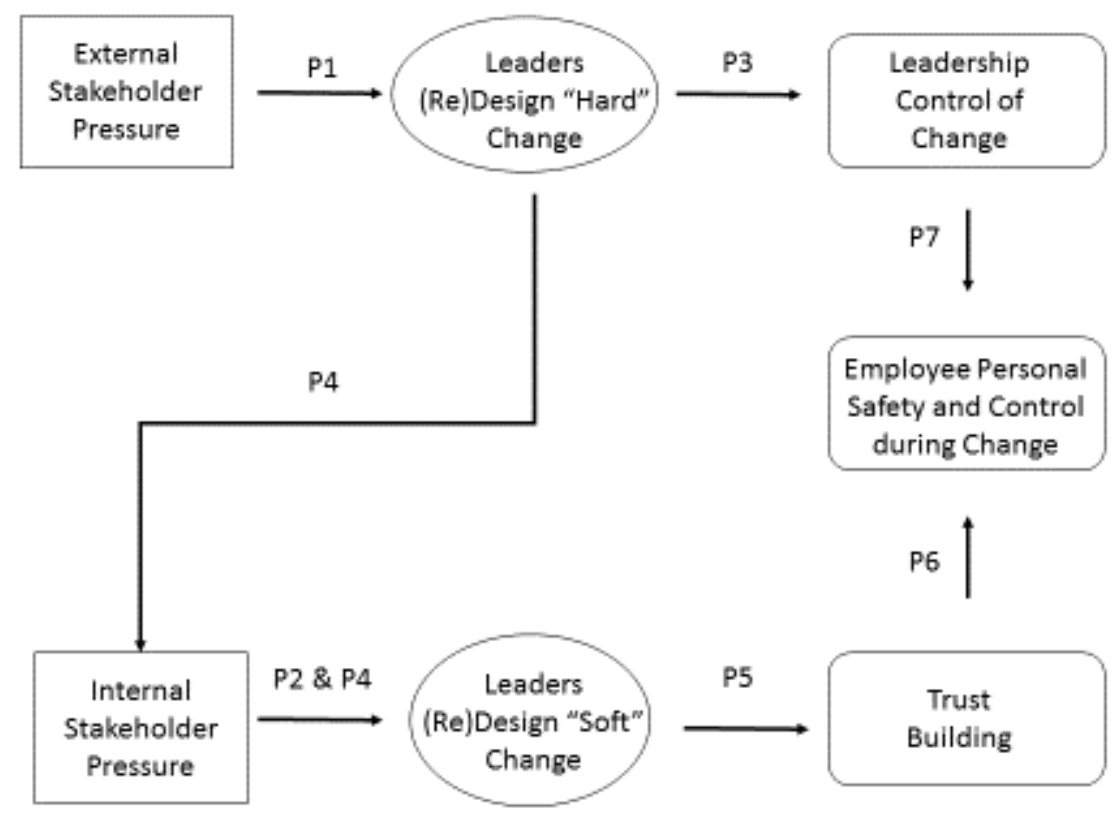

Figure 1: Conceptual Framework for Leading Organisational Change 


\subsection{Step 2: Propositions}

From the frameworks, the propositions that will be researched are identified. In qualitative research, a proposition is a statement of the qualitative (and not quantitative or statistical) nature of the relationship between various concepts contained in the literature. According to Yin (2014), these propositions direct the attention of the researcher to what should be focused upon within the study, and later serve as a basis for making analytical generalisations.

The researcher must be confident that each of the propositions are derived from the theory. The positioning of the propositions in the conceptual framework should also be evident. Furthermore, the literature review may be structured in such a way as to "argue the case" for each of the propositions. Consequently, when written up, step one and two are often integrated into the literature review section of a paper, or the literature chapter of a thesis/dissertation. See the articles by DeRue and Ashford (2010), Murphy and Ensher (2008) and Yukl (2008) for examples of how to develop propositions.

Based upon a review of the literature that resulted in the design of the conceptual framework presented above, a number of propositions can be developed in support of the research problem, namely:

- Proposition one (P1): Leaders who recognise pressure from external stakeholders to change, are more likely to design "hard" interventions.

- Proposition two (P2): Leaders who recognise pressure from internal stakeholders to change, are more likely to design "soft" interventions.

- Proposition three (P3): Leaders who introduce "hard" change elements in response to external stakeholders, are seen to be in control of the change.

- Proposition four (P4): Leaders who perceive internal resistance to the introduction of "hard" change elements, respond by designing "soft" interventions.

- Proposition five (P5): Leaders who (re)design "soft" elements of the changes they introduce, build trust with employees.

- Proposition six (P6): When leaders build trust with employees during the change process, this enables employees to regain a sense of personal safety and control.

- Proposition seven (P7): Leaders who are seen to be in control of the change, enable followers to have a sense of personal safety and control during the change process.

\subsection{Step 3: Code Book}

Given the stated propositions, the researcher can now develop a code book that will be used to code the raw data (see Boyatzis 1998; Crabtree and Miller 1992; Fereday and Muir-Cochrane 2006). That is, each of the key concepts is given an abbreviation (or code) to facilitate the labelling of the data. A preliminary code book is generated based on the conceptual model that was developed from the literature review (Crabtree \& Miller 1992). Typically, this data is in the form of text, such as the transcription of an interview, or a document that is to be analysed. If the transcript has been printed out, the code can be written in the margin, next to the text where it was identified by the researcher. The relevant text can also be underlined or highlighted, with a range of colours used for different codes. If the text is in a digital format such as Microsoft Word, the "new comment" function in the "Reviewer" menu may be used to select and label the text that reflects the code. Qualitative software analysis tools such as NVivo, Atlas.ti, and Dedoose provide a similar way of labelling or coding the data, and then provide the researcher with additional functions to sort, group and analyse the data.

Crabtree and Miller (1992) and Pearse (2019) illustrate the generation of a full set of codes from a set of propositions. To illustrate, the example of leading organisational change has a total of nine codes originating from the theory, namely: pressure from external stakeholders, "hard" interventions, pressure from internal stakeholders, "soft" interventions, control, redesign, trust and a sense of personal safety and control. Proposition one and two would require codes as follows:

- Ext = pressure from external stakeholders to change

- $\mathrm{H}=$ "hard" interventions

- Int = pressure from internal stakeholders to change

- $\mathrm{S}=$ "soft" interventions 
As indicated by Boyatzis (1998) and Fereday and Muir-Cochrane (2006), this codebook can be expanded into a coding memorandum, whereby each code has (1) a label or name; (2) a definition; (3) a description of how it occurs; (4) qualifiers and exclusions to provide guidance when deciding if a piece of data qualifies for inclusion or not. This memorandum is developed prior to the fieldwork. Once data has been collected, the researcher can look for an example in the data, and include that in the memorandum to verify, or demonstrate the applicability of the coding memorandum to the data collected. This coding memorandum can be tabulated as shown in Table 1 with a column for each code. In the case of a large number of codes, the table can be pivoted, with a code per row.

Table 1: An illustration of a Coding Memorandum

\begin{tabular}{|l|l|l|}
\hline Code & S & H \\
\hline Label & "soft" interventions & "hard" interventions \\
\hline Definition & $\begin{array}{l}\text { Change interventions that focus on people } \\
\text { and their behaviour. }\end{array}$ & $\begin{array}{l}\text { Change interventions that focus on non- } \\
\text { behavioural elements of organisations. }\end{array}$ \\
\hline $\begin{array}{l}\text { Description of } \\
\text { occurrence }\end{array}$ & $\begin{array}{l}\text { Changes that focus directly on preparing } \\
\text { employees for change and enabling them to } \\
\text { deal effectively with the change, through } \\
\text { elements such as the vision, values and } \\
\text { culture, organisation policies and practices, } \\
\text { education and training initiatives and } \\
\text { socialisation patterns. }\end{array}$ & $\begin{array}{l}\text { Changes that focus directly on raw materials, } \\
\text { resources other than human resources, products, } \\
\text { organisation structure, systems and processes. }\end{array}$ \\
\hline $\begin{array}{l}\text { Qualifiers and } \\
\text { exclusions }\end{array}$ & $\begin{array}{l}\text { "Soft" changes are directly and explicitly } \\
\text { targeted at people. }\end{array}$ & $\begin{array}{l}\text { People may be affected by these changes, but } \\
\text { are not the direct target of the intervention. }\end{array}$ \\
\hline $\begin{array}{l}\text { Data examples to } \\
\text { verify the code }\end{array}$ & $\begin{array}{l}\text { A leader identified three people who he met } \\
\text { with regularly to mentor. }\end{array}$ & $\begin{array}{l}\text { A leader introduced a new organisational } \\
\text { structure. }\end{array}$ \\
\hline
\end{tabular}

\subsection{Step 4: Question Matrix}

If data is to be collected by interviews, then using the codebook and coding memorandum as a point of reference, interview questions can be generated, taking all competing theories and their propositions into account. While the interview will be semi-structured in nature, it is essential in deductive qualitative studies that the researcher prepare interview questions pertaining to all the propositions of the study, and that all of these questions are asked in the interview. In the event of the researcher emerging from data collection and having not covered all the questions, it is quite likely that conclusions cannot be drawn for all the propositions because of missing data. A question matrix can be developed to help ensure that the questions that are to be asked in the interviews are comprehensive in their coverage of the propositions. The use of a matrix will also help to confirm that the researcher will ask questions that are relevant to determining if the propositions of the research do provide an explanation for the data, or not.

Castillo-Montoya (2016) and Pearse (2019) provide examples of a comprehensive question matrix. In the case of the "leading organisational change" example, questions will need to be formulated to cover all seven propositions. However, in formulating the interview questions and when conducting the interview, the researcher should not lose sight of the qualitative nature of the research. That is, the researcher may be tempted to simply "test" the applicability of the proposition in order to conclude if it is a relevant explanation for the case at hand, or not. Even with explanatory case studies (Yin, 2014), as a qualitative study, the research interest is in answering "how?" and "why?" questions.

To illustrate the formulation of interview questions for the "leading organisational change" example, Proposition Five states the following: "Leaders who (re)design "soft" elements of the changes they introduce, build trust with employees." The interview can be initiated with a series of open-ended, exploratory questions that guide the interviewee to provide the background information to the change initiative, and to describe what was done by the leadership of the organisation. Open questions such as the following could be asked, and followed up with further probing questions:

- Please tell me about a change that you have introduced in your organisation.

- What were the reasons for introducing the change?

- What influence did various stakeholders have in determining the need for, and in the design of this change initiative? 
- What does the change initiative entail and how was implemented?

Once the interviewee describes the introduction of a "soft" element as part of the change, this will serve as a "trigger" to ask questions relevant to proposition five, such as:

- When you introduced this change element, what reaction did you receive from employees, supervisors and managers?

- How did the introduction of the change affect the trust relationship that you have with employees?

- Was there any evidence of resistance to the change? If so, what form did it take and what did you do about it?

If the trust relationship has been negatively affected by the change, then the following question can be asked:

- What did you do if anything, to rebuild trust?

Proposition six is a continuation of the process covered by proposition five. To establish if the leader was of the view that employees felt safe and in control as a result of trust building initiatives, the following questions can be asked:

- How did your trust building initiatives contribute to employees feeling safe and in control?

- In the end, how did the employees feel about the change initiative?

- At any stage did you observe that employees felt anxious, or felt that they had lost control of their work situation because of the change? If so, what did you do about it?

In a similar manner to what has been illustrated here for propositions five and six, lists of interview questions would need to be generated for all of the other propositions. In the case of a study where the data has not been collected through interviews, but for example, through the analysis of documents, the researcher may "interrogate" the data using a similar line of questions.

\subsection{Step 5: Data Collection}

Using the question matrix or equivalent guidelines and protocols, research data is collected. Referring to the series of interview questions in Step 4, by the end of this section of the interview, the researcher should have a good idea if the proposition was applicable to the change incident described, or not. If it was relevant, then the researcher will have an account of its application. On the other hand, if it was not applicable to the change incident described, then the interviewee should have given an explanation of what they did instead, and why. In summary, through the series of questions the researcher will have answers to not only "if" the proposition was applicable, but also to the "how?" and "why?" questions that characterise qualitative research.

However, it is possible that a particular interviewee may not be able to give a full account of an incident or event. For example, the interviewee may have only been involved, or acquainted with some aspects of a change initiative and not others. Since the case study method supports the collection of different types and sources of data (Yin 2014), in some investigations the researcher may need to assemble data from a variety of sources and types in order to create a full account of an incident or event. While the case illustrated here relied on interviews with leaders, data could also have been collected through interviews with other stakeholders, as well as from documents such as annual reports, emails, minutes of meetings, newsletters and similar publications.

\subsection{Step 6: Analysis}

The analysis of data consists of three stages. Firstly, the code book and coding memorandum is applied to the analysis of the data collected. This involves reviewing, revising and/or confirming that the codes do in fact appear in the data by finding examples (Boyatzis 1998). This is illustrated in the row labelled "Data examples to verify the code" in Table 1. Yukhymenko et al. (2014) promote an extension of the analysis beyond the theoretical propositions that are derived from the literature review. They make a distinction between "confirmed themes" and "added themes" and encourage researchers to add to the code book, if additional codes are identified in the data. From the perspective of a deductive qualitative approach, this should be 
viewed as an exception, rather than a normal practice, as the ability of extant theory to offer an explanation, is first and foremost what is being confirmed in the research.

Secondly, themes are identified. A theme "represents some level of patterned response or meaning within the data set" (Braun \& Clarke 2006, p. 82). Themes therefore arise from connecting codes to one another and thereby identifying patterns in the data (Fereday \& Muir-Cochrane 2006). In the case of inductive studies, the codes are identified from the data, and the researcher connects codes to create themes, through a process of constant comparison of one piece of data with another (Boyatzis, 1998). On the other hand, with deductive thematic analysis, the codes and their connections have already been derived from the literature, and are represented by the propositions. Therefore, when analysing the data, the researcher is not exploring the data to generate themes, but rather is interested in "matching" data to the propositions (which are in essence the themes), in order to establish if the propositions explain the data. That is, the researcher is interested in determining if the data confirms or refutes the propositions, and by extension the theories (Boyatzis, 1998).

In some qualitative studies, particularly case studies, it may be necessary to describe the case first to create a context for the themes that are developed and presented, before describing the themes. In other cases, it may be possible to simply develop and present the themes without the descriptive background.

By way of example, short extracts of five descriptive accounts of incidents or events that occurred while leading change in various organisations, are offered. Each one is given a title for ease of reference:

- Mentorship: The leader had to assume leadership from someone who had left the organisation after unsuccessfully trying to implement an unpopular structural change. The interviewee privately believed that this change initiative was the correct one for the organisation, but to create stability, he publicly committed to not making any changes for six months. Rather he indicated that he would be talking to people to get to know them better, and to get their views on what changes were required. Within the next six months he identified three people who he met with regularly to mentor through teaching and relationship building. In his communication with these three people and the larger organisation, he emphasised the importance of values, and in particular highlighted the importance of transparency, respect and being an example to others, as three key values. These values were the basis for future interventions.

- Restructuring: When introducing a new organisational structure in support of a new strategy, the leader did not force members into the new structure, but rather set it up as alternative to the existing structure, and therefore allowed the two structures to continue in parallel with one another for a period of time.

- Retraining: When observing a dysfunctional team that did not serve the organisation's mission, the leader disbanded the team and arranged training to instruct the former team members about the new direction that the organisation was heading in, and to develop the requisite skills in the members.

- Performance Monitoring: The leader closely monitored the performance of the organisation, as well as its members. Key performance indicators at the organisational and individual level were tracked on a weekly basis. Those individuals, who were unable and/or unwilling to perform in an assigned role, were redeployed to other areas of responsibility that better suited their abilities.

- Attention and Neglect: A leader set clear priorities for himself, and then spent a great deal of time with members who were engaged in activities that were aligned to the new vision. On the other hand, individuals who were not aligned to the vision were neglected. The leader did not actively oppose what they were doing, and allowed them to continue with those activities that interested them. He never attended these activities or showed any interest in them, but nor did he try to end them.

From the perspective of a deductive approach, identifying themes involves looking for evidence in the data of the patterns that were set out in the propositions of the study. Applying, pattern matching at this point, the researcher compares the dataset with the competing frameworks, or theories. Firstly, this is illustrated in Table 2 , where there are two columns representing each of the competing theories. The third column notes any contrary observations, and a fourth column has been included for any observations of additional themes that may have an alternative explanation to that provided by the two theories. 
Table 2: Comparing Competing Theories

\begin{tabular}{|c|c|c|c|c|}
\hline Title & $\begin{array}{l}\text { Theory of "soft" } \\
\text { change and trust }\end{array}$ & $\begin{array}{l}\text { Theory of "hard } \\
\text { change" and control }\end{array}$ & Contrary examples & $\begin{array}{l}\text { Additional themes } \\
\text { and explanations }\end{array}$ \\
\hline Mentorship & $\begin{array}{l}\text { Mentoring through } \\
\text { teaching and } \\
\text { relationship building. }\end{array}$ & & & $\begin{array}{l}\text { Values as control: } \\
\text { While values may } \\
\text { contribute to building } \\
\text { trust, they could also } \\
\text { represent a different } \\
\text { form of control }\end{array}$ \\
\hline Restructuring & & & $\begin{array}{l}\text { Low control: } \\
\text { Providing alternatives }\end{array}$ & \\
\hline Retraining & & $\begin{array}{l}\text { Disbanding } \\
\text { dysfunctional teams }\end{array}$ & & \\
\hline Monitoring & & $\begin{array}{l}\text { Monitoring } \\
\text { organisational and } \\
\text { individual } \\
\text { performance, and the } \\
\text { redeployment of poor } \\
\text { performers. }\end{array}$ & & \\
\hline Attention and Neglect & $\begin{array}{l}\text { Investing time in } \\
\text { members aligned to } \\
\text { the vision. }\end{array}$ & & $\begin{array}{l}\text { Low Trust: neglecting } \\
\text { individuals who are } \\
\text { not aligned to the } \\
\text { vision, but allowing } \\
\text { them to continue with } \\
\text { activities that interest } \\
\text { them. }\end{array}$ & $\begin{array}{l}\text { Time as a limited } \\
\text { resource: what the } \\
\text { leader spends time on } \\
\text { indicates to members } \\
\text { what is valued. }\end{array}$ \\
\hline
\end{tabular}

Secondly, for the propositions of each theory, a record of hits and misses can be kept to identify which theory best fits the data (Hyde, 2000), while also applying theoretical triangulation to analyse how the theories complement each other (Hopper and Hoque, 2006). The table recording hits and misses should capture all the data for all the incidents or events, across all of the propositions.

Table 3 illustrates how this can be done. Note that once again, the illustration is not comprehensive, as the table only captures data reflected in short extracts of the five descriptive accounts that were provided earlier. In the case of the account entitled "Attention and Neglect", this has been split into two rows to clearly reflect the two different sets of responses contained in the incident. In the lower section of the table, the totals related to each of the theories and their associated propositions are calculated, by adding up the number of "Yes" responses in the column. For example, the number of hits for the "hard" control theory that is represented by propositions one, three and seven, is 0, 3 and 0 respectively. In contrast, the total hits for "soft" trust theory represented by propositions two, five and six, are 2, 4 and 1 respectively. Furthermore, the integration of the two theories as represented by proposition four has one hit.

Table 3: A Record of Hits and Misses

\begin{tabular}{|l|l|l|l|l|l|l|l|}
\hline Title of incident or event & \multicolumn{6}{|l|}{ Propositions } \\
\hline & P1 & P2 & P3 & P4 & P5 & P6 & P7 \\
\hline Mentorship & & Y & N & Y & Y & & \\
\hline Restructuring & & & N & N & & & \\
\hline Retraining & & & Y & & Y & & \\
\hline Performance Monitoring & & & Y & N & Y & & \\
\hline Attention & & Y & N & & Y & & \\
\hline and Neglect & & N & Y & & N & N & \\
\hline & & 3 & & & & 0 \\
\hline $\begin{array}{l}\text { Total hits for "hard" control } \\
\text { theory } \\
\text { [Propositions 1, 3, \& 7] }\end{array}$ & 0 & & & & & & \\
\hline $\begin{array}{l}\text { Total hits for "soft" trust } \\
\text { theory } \\
\text { [Propositions 2, 5, \& 6] }\end{array}$ & 2 & & & 4 & 1 & \\
\hline $\begin{array}{l}\text { Total hits for Integration of } \\
\text { theories } \\
\text { [Proposition 4] }\end{array}$ & & & & 1 & & & \\
\hline $\begin{array}{l}\text { Key: Y= confirmation of the proposition; N= proposition contradicted; O = incident had nothing related } \\
\text { to the proposition. }\end{array}$ & & & & & & \\
\hline
\end{tabular}


Based purely on the five short extracts; it is clear that so far, there is more support for the "soft" trust theory than for the "hard" control theory. What is more, three of the incidents refute proposition three. However, there are also gaps evident. For example, three extracts provide support for proposition three, but there is no data yet from these three specific incidents for propositions one and seven that are also associated with the "hard" control theory. Keeping a running tally of hits and misses during data collection and analysis can therefore assist the researcher to spot gaps, which can guide the analysis of the existing data and point out areas for further data collection. For example, the researcher should analyse the data related to the incidents of "Retraining", "Performance Monitoring" and "Neglect" to see if there is any support for propositions one or seven. If there is no relevant data, the researcher may recognise the need for collecting further data about the incidents. Ultimately, the table of hits and misses will record that "Yes", supporting evidence was found; "No" contrary evidence was found; or " 0 ", the incident had no data related to the proposition.

\subsection{Step 7: Reporting}

The findings are written up by initially focusing on one theory at a time, with the intention of showing how the data confirms or refutes each proposition, and by extension the theory. When writing up each theory, the researcher should report both supporting and contradicting evidence. For example, when writing up the section on "hard" control theory, and using the analysis of the five short extracts as an example, the researcher would make the following points:

- In the cases analysed, "hard" change was evident in the form of organisational restructuring, the redeployment of resources, and creating systems and processes.

- While in some instances, the introduction of these changes were viewed as decisive actions that showed that the leader was in control, in other instances the leader deliberately relinquished control by giving individuals a greater freedom of choice, or by suspending and postponing particular actions.

To complete the write up of the "hard" control theory theme, the researcher would also need to explain:

- What circumstances brought about the introduction of the "hard" change in the first place.

- Whether or not the display of leadership control instilled confidence amongst followers, and gave them a sense of personal safety and control.

- What the outcome was of leadership actions that were deliberately low in control.

Furthermore, as each theory is presented, the researcher would make reference to various incidents and events, illustrating how the theory "played out" in reality. That is, the themes are written up as a narrative, including summaries of the supporting and contradicting evidence, and incorporating pertinent quotations to bring the themes to life.

These sections on the two theories would be followed by an integrated section showing how the theories "work together"; but also acknowledging any contradictions or tensions between them that may arise. In the example on leading organisational change, proposition four represents one way in which the two theories could be integrated, with a "hard" change programme triggering a "soft" redesign, due to pressure from internal stakeholders. Once again, the researcher would look for and report on cases that both support and refute the proposition. For example, the "Mentoring" case supported the proposition, where a leader recognised there was resistance to structural changes, put these on hold and focused on relationship building and mentoring. In contrast, in the "Restructuring" case, when there was resistance to new structural arrangements, the leader did not design "soft" changes to deal with this resistance, but rather allowed the old structure to continue in parallel with the new one. As an example of a tension and distinction between the relative contribution of the two theories, from the review of the literature there was no indication that a "soft" change could lead to pressure from external stakeholders and the need for leaders to design a "hard" change component.

Consistent with the deductive approach to the research, when concluding the study, the researcher should indicate if the various theories did indeed provide an explanation for the data collected and analysed, or not, and which theory or theories best fits the data. Finally, the report can also incorporate the list of codes, coding 
memorandum, the question matrix, a sample of how the coding was applied to the data, and the table of hits and misses. This will enhance the dependability (Riege, 2003) of the research.

\section{Conclusion}

From the perspective of teaching and applying research methods, this paper provides a set of guidelines, examples and illustrations for researchers to follow, so that they can carry out deductive qualitative research.

The procedure set out here, is also useful to those who have to carry out research on a single case, in studies of limited scope, such as an MBA half-thesis. Hopefully, this paper encourages qualitative researchers to adopt deductive approaches to their research, thereby building on the work of others, and contributing to the accumulation of a distinctive body of knowledge on leadership and organisational processes that can be attributed to qualitative research.

\section{References}

Almutairi, AF, Gardner, GE, \& McCarthy, A 2014, "Practical guidance for the use of a pattern-matching technique in casestudy research: A case presentation: Pattern-matching technique”, Nursing \& Health Sciences, vol. 16, no. 2, pp. 239244.

Arnstein SR, 1969, “A Ladder of Citizen Participation”, Journal of the American Planning Association, vol. 35, no. 4, pp. 216 224.

Beer, M, \& Nohria, N, 2000, "Cracking the code of change." HBR's 10 must reads on change, vol. 78, no. 3, pp. 133-141.

Boyatzis, RE 1998, Transforming Qualitative Information: Thematic Analysis and code development, Thousand Oaks, SAGE Publications.

Braun, V \& Clarke, V 2006, "Using thematic analysis in psychology", Qualitative Research in Psychology, vol. 3, no. 2, pp. 77-101.

Brown, AD 2018, "Identities in Organization Studies", Organization Studies, pp. 1-15.

Bryman, A 2004, "Qualitative research on leadership: A critical but appreciative review", The Leadership Quarterly, vol. 15, no. 6, pp. 729-769.

Campbell, DT 1975, "III. 'Degrees of freedom' and the case study", Comparative Political Studies, vol. 8, no. 2, pp. $178-193$.

Caruth, D, Middlebrook, B, \& Rachel, F 1985, "Overcoming resistance to change ." SAM Advanced Management Journal, vol. 50, no. 3, pp. 23-27.

Castillo-Montoya, M 2016, "Preparing for interview research: The interview protocol refinement framework", The Qualitative Report, vol. 21, no. 5, pp. 811-831.

Crabtree, BF \& Miller, WL 1992, "A template approach to text analysis: Developing and using codebooks", in B. F. Crabtree \& W. L. Miller (eds.), Doing Qualitative Research, pp. 93-109, SAGE Publications, Newbury Park, California.

Denis, J-L, Langley, A, \& Pineault, M 2000, “Becoming a leader in a complex organization”, Journal of Management Studies, vol. 37, no. 8, pp. 1063-1100.

DeRue, DS \& Ashford, SJ 2010, "Who will lead and who will follow? A social process of leadership identity construction in organizations", Academy of Management Review, vol. 35, no. 4, pp. 627-647.

Dyer, WG \& Wilkins, AL 1991, "Better Stories, Not Better Constructs, to Generate Better Theory: A Rejoinder to Eisenhardt", The Academy of Management Review, vol. 16, no. 3.

Edwards, MB 2015, "The role of sport in community capacity building: An examination of sport for development research and practice", Sport Management Review, vol. 18, no. 1, pp. 6-19.

Fereday, J \& Muir-Cochrane, E 2006, "Demonstrating rigor using thematic analysis: A hybrid approach of inductive and deductive coding and theme development", International Journal of Qualitative Methods, vol. 5, no. 1, pp. 80-92.

Fischer, T, Dietz, J, \& Antonakis, J 2017, "Leadership process models: A review and synthesis", Journal of Management, vol. 43, no. 6 , pp. 1726-1753.

Fisher, I \& Ziviani, J 2004, "Explanatory case studies: Implications and applications for clinical research", Australian Occupational Therapy Journal, vol. 51, no. 4, pp. 185-191.

Freeman, RE, 1984, Strategic Management: A stakeholder approach. Boston: Pitman.

Freeman, RE, 2004, "The stakeholder approach revisited", Zeitschrift für Wirtschafts-und Unternehmensethik, vol. 5, no. 3, pp. 228 - 254.

Freeman, RE, Harrison, JS and Wicks, AC, 2007, Managing for stakeholders: Survival, reputation, and success. New Haven: Yale University Press.

Gibbert, M, Ruigrok, W, \& Wicki, B 2008, “What passes as a rigorous case study?”, Strategic Management Journal, vol. 29, no. 13, pp. $1465-1474$.

Higgs, M \& Rowland, D 2011, "What does it take to implement change successfully? A study of the behaviors of successful change leaders", The Journal of Applied Behavioral Science, vol. 47, no. 3, pp. 309-335.

Hopper, T \& Hoque, Z 2006, "Triangulation approaches to accounting research", in Z. Hoque (ed.), Methodological issues in accounting research: theories and methods, pp. 477-486, Spiramus Press Ltd.

Hui, C \& Lee, C 2000, “Moderating Effects of Organization-Based Self-Esteem on Organizational Uncertainty: Employee Response Relationships", Journal of Management, vol. 26, no. 2, pp. 215-232. 
Huy, QN 2001, “Time Temporal Capability, and Planned Change”, Academy of Management Review, vol. 26, no. 4, pp. 601623.

Hyde, KF 2000, "Recognising deductive processes in qualitative research", Qualitative Market Research: An International Journal, vol. 3, no. 2, pp. 82-90.

Jones, GJ, Edwards, MB, Bocarro, JN, Bunds, KS, \& Smith, JW 2018, "Leveraging community sport organizations to promote community capacity: Strategic outcomes, challenges, and theoretical considerations", Sport Management Review, vol. 21, no. 3, pp. 279-292.

Judge, WQ \& Elenkov, D 2005, “Organizational capacity for change and environmental performance: an empirical assessment of Bulgarian firms", Journal of Business Research, vol. 58, no. 7, pp. 893-901.

Kotter, J, 2007. "Why transformation efforts fail”, Harvard Business Review, vol. 85, no. 1, pp. 96 - 102.

Kotter, JP \& Schlesinger, LA, 2008, “Choosing Strategies for Change", Harvard Business Review, vol. 86, no. 2, pp. 130-139.

Krick, T, Forstater, M, Monaghan, P \& Sillanpää, M, 2005, "The stakeholder engagement manual volume 2: The practitioners' handbook on stakeholder engagement. Account Ability", the United Nations Environment Programme, and Stakeholder Research Associates.

Mathews, J 2009, "Models of Change Management: A Reanalysis", The Icfai University Journal of Business Strategy, vol. 6, no. 2, pp. 7-17.

Miles, MB, Huberman, AM, \& Saldaña, J 2014, Qualitative data analysis: a methods sourcebook. Third edition SAGE Publications, Inc, Thousand Oaks.

Mitchell, RK, Agle, BR and Wood, DJ, 1997, "Toward a theory of stakeholder identification and salience: Defining the principle of who and what really counts". Academy of Management Review, vol. 22, no. 4, pp. 853-886.

Murphy, SE \& Ensher, EA 2008, "A qualitative analysis of charismatic leadership in creative teams: The case of television directors", The Leadership Quarterly, vol. 19, no. 3, pp. 335-352.

Neves, P \& Caetano, A 2006, "Social Exchange Processes in Organizational Change: The Roles of Trust and Control", Journal of Change Management, vol. 6, no. 4, pp. 351-364.

Newcombe, R, 2003, "From client to project stakeholders: a stakeholder mapping approach". Construction Management and Economics, vol. 21 no. 8, pp.841-848.

Pearse, NJ, 2010, "Towards a social capital theory of resistance to change", Journal of Advances in Management Research, vol. 7, no. 2, pp. 163-175.

Pearse, NJ, 2019, "An Illustration of Deductive Analysis in Qualitative Research". Presented at the 18th European Conference on Research Methodology for Business and Management Studies (ECRM19), Wits Business School, Johannesburg, 20th -21st June 2019.

Riege, AM 2003, "Validity and reliability tests in case study research: a literature review with "hands-on" applications for each research phase", Qualitative Market Research: An International Journal, vol. 6, no. 2, pp. 75-86.

Rishi, M, Jauhari, V, \& Joshi, G 2015, "Marketing sustainability in the luxury lodging industry: a thematic analysis of preferences amongst the Indian transition generation", Journal of Consumer Marketing, vol. 32, no. 5, pp. 376-391.

Smulders, F, Caluwe, L, \& Nieuwenhuizen, O 2003, "The Last Stage of Product Development: Interventions in Existing Operational Processes", Creativity and Innovation Management, vol. 12, no. 2, pp. 109-120.

Truss, C 1999, "Human resource management: gendered terrain?" The International Journal of Human Resource Management, vol. 10, no. 2, pp. 180-200.

Uysal, N \& Tsetsura, K 2015, “Corporate governance on stakeholder issues: shareholder activism as a guiding force: Shareholder activism as a guiding force", Journal of Public Affairs, vol. 15, no. 2, pp. 210-219.

Yin, RK 1981, "The case study as a serious research strategy", Knowledge, vol. 3, no. 1, pp. 97-114

Yin, RK 2003, Case study research: design and method, 3rd edn, Sage, Thousand Oaks

Yin, RK 2014, Case Study Research, Design and Methods, 5th edn, Thousand Oaks, SAGE Publications

Yukhymenko, MA, Brown, SW, Lawless, KA, Brodowinska, K, \& Mullin, G 2014, "Thematic Analysis of Teacher Instructional Practices and Student Responses in Middle School Classrooms with Problem-Based Learning Environment." Global Education Review, vol. 1, no. 3, pp. 93-110.

Yukl, G 2008, “How leaders influence organizational effectiveness”, The Leadership Quarterly, vol. 19, no. 6, pp. 708-722. 